\title{
ANÁLISIS DEL EFECTO DE LA TRADUCCIÓN (INGLÉS-ESPAÑOL) EN LA LEGIBILIDAD DEL PROSPECTO DE MEDICAMENTO
}

\author{
Raquel Martínez Motos \\ Universidad de Alicante \\ raquel.motos@ua.es
}

\section{Resumen}

El presente artículo es una aproximación al estudio de los posibles efectos de la traducción inglés-español en la legibilidad de los prospectos de medicamentos. Se basa en la realización de un análisis cuantitativo y cualitativo de los elementos que intervienen en el grado de legibilidad de un corpus de 150 prospectos seleccionados de acuerdo con unos criterios ajustados a ese fin. Los resultados y conclusiones extraídos tras el análisis servirán para determinar si el proceso de traducción puede influir en el grado de legibilidad en los textos traducidos frente a los originales y, de ser así, en qué medida lo hace.

\begin{abstract}
"Analysis of the effects of translation (English-Spanish) on the readability of patient information leaflets"

This paper focuses on the potential effects of translation from English into Spanish in the readability of patient information leaflets. It is based on the quantitative and qualitative analysis of the elements involved in the degree of readability of a corpus of 150 patient information leaflets specifically selected for this purpose. The results obtained and the conclusions reached after the analysis may be used to determine whether the translation process has any impact on the degree of readability of translated texts against original ones and, if so, to which degree does it affect.
\end{abstract}

Palabras clave: Prospecto de medicamento. Traducción. Legibilidad. Género. Corpus.

Keywords: Patient information leaflet. Translation. Readability. Genre. Corpus. 



\section{Introducción}

El presente artículo tiene su origen en un artículo anterior (cf. Martínez Motos 2012) en el que se llevaba a cabo una revisión de los modelos de evaluación de la calidad de los prospectos en inglés y en español, y se proponía la aplicación de un nuevo modelo que analizara el efecto de la traducción en la producción de prospectos legibles y fáciles de usar.

La implementación de dicho modelo incluía diversas fases y metodologías. La primera fase consistía en el análisis de determinados aspectos de naturaleza cualitativa y cuantitativa en un corpus seleccionado según unos criterios previamente establecidos de acuerdo con el objetivo investigador. La segunda fase incluía información relativa a los usuarios a través de un cuestionario. La tercera añadía datos de tipo extratextual mediante un estudio de casos orientado a la descripción del entorno profesional en el que se traducen textos similares a los analizados previamente. Finalmente, la triangulación de los resultados permitiría extraer conclusiones presumiblemente diferentes a las presentadas en trabajos anteriores que abordaban el estudio de los prospectos desde otras perspectivas.

El objetivo de este artículo es presentar parte de los resultados obtenidos en el análisis cuantitativo de un corpus, es decir, de la implementación de la primera fase. Más concretamente, los relacionados con el grado de legibilidad que se observa en los prospectos originales en español frente a los traducidos a ese mismo idioma desde el inglés. En otras palabras, determinar si el proceso de traducción puede influir en el grado de legibilidad de los textos traducidos frente a los originales.

En los apartados siguientes se revisa el concepto de legibilidad y se realiza una triple aproximación al prospecto como objeto de estudio, como objeto de armonización jurídica y como género, con una breve descripción de los trabajos previos más relevantes. En el estudio empírico, se presentan los criterios de selección del corpus analizado, así como una descripción de la metodología empleada para su análisis. Posteriormente, se exponen los resultados cuantitativos y una descripción cualitativa de estos. En el último apartado se abordan las conclusiones extraídas del estudio. 


\section{Conceptos y elementos clave de objetivo investigador}

Trabajos de autores como Askehave \& Zethsen $(2000,2002)$, Clerehan, Hirsh $\&$ Buchbinder (2009), Gal \& Prigat (2005), Hoste et al. (2010) y Pander Maat \& Lentz (2010) constituyen el punto de partida del presente artículo. Según estos autores los prospectos no se ajustan a las necesidades lingüísticas y comunicativas de sus potenciales destinatarios, a pesar de los esfuerzos realizados tanto por la industria farmacéutica como por las autoridades competentes. En otras palabras, los prospectos presentan dificultades de legibilidad y facilidad de uso para el receptor lego. La búsqueda de una posible respuesta a esta cuestión lleva a plantearse la siguiente hipótesis general: los prospectos presentan problemas de legibilidad para el receptor lego y el uso inadecuado del lenguaje sería la principal causa de ello. Si a esto le añadimos que algunos prospectos son el resultado de un doble proceso de redacción y posterior traducción, cabe plantearse también la siguiente pregunta: ies el proceso de traducción inglésespañol un factor determinante en la elaboración de prospectos con un grado de legibilidad más elevado?, ¿cuáles presentan más problemas de legibilidad, los originales o los traducidos?

Ante estas preguntas es preciso explicar el concepto de legibilidad. Para ello es necesario partir de dos términos en inglés: readability y legibility. Al referirse al primero, Dubai (2004: 3) lo define como "what makes some texts easier to read than others. It is often confused with legibility, which concerns typeface and layout". De igual modo, Göpferich (2009: 48) distingue entre ambos conceptos y señala que "layout and design characteristics (macro-typography), the fonts used and other paraverbal features (micro-typography), as well as nonverbal elements" son los elementos que determinan la legibility. Sin embargo, a pesar de tratarse de dos términos que expresan conceptos diferentes, los diccionarios bilingües Oxford y Collins Cobuild únicamente ofrecen un posible equivalente en español: legibilidad. La Real Academia Española define este término como "cualidad de lo que es legible" y por legible entiende lo "que se puede leer". Por lo tanto, partimos de un único término en español tradicionalmente empleado como equivalente de dos términos en inglés que expresan conceptos distintos.

Para tratar de resolver esta cuestión, autores como Suárez Muñoz \& Suárez Ramírez (2013: 417) distinguen entre legibilidad, ligada a los elementos tipográficos y visuales (color, gráficos, organización), como equivalente de legibility, y lecturabilidad (no recogido en el Diccionario de la Real Academia Española), que depende de los elementos relacionados con el contenido textual que determinan la facilidad del texto para ser leído y comprendido sin esfuerzo, como equivalente de readability. Otros, como Barrio Cantalejo et al. (2008b: 
136) únicamente emplean el término legibilidad, pero diferencian ambos conceptos en inglés en función de si el adjetivo que lo determina es tipográfica o lingüistica, a saber:

La legibilidad es el conjunto de características tipográficas y lingüísticas del texto escrito que permiten leerlo y comprenderlo con facilidad. La legibilidad tiene dos dimensiones complementarias. La legibilidad tipográfica, que viene condicionada por el tamaño, forma, diseño y disposición espacial de los caracteres gráficos del texto y la legibilidad lingüística, en la que, a su vez, se distinguen dos subtipos: la legibilidad gramatical, que tiene que ver con la estructura y la construcción gramatical del texto y la legibilidad léxica, que se interesa por el significado de las palabras.

A lo largo del presente artículo se empleará el término legibilidad en referencia a la legibilidad lingüística, tal cual la conciben Barrio Cantalejo et al. (2008b), ya que se adecua mejor al objetivo investigador y, además, lo relacionan con la evaluación de textos dirigidos a pacientes mediante el empleo de una metodología de análisis que incluye la Escala INFLESZ, que explicaremos más adelante.

\section{Triple aproximación descriptiva al prospecto}

En las últimas dos décadas se ha observado un notable incremento en la literatura tanto en inglés como en español en torno a los prospectos de medicamentos. Entre los argumentos que justificarían el creciente interés por el estudio y análisis de esta clase de documentos parece ganar peso el señalado por Jensen (2012: 237), para quien "patients today demand transparency and enough information in order to make informed choices about a proposed treatment option, or about taking a specific medication, etc."

En otras palabras, los pacientes, potenciales destinatarios y usuarios de prospectos (entre otros textos de divulgación médica), han pasado a desempeñar un papel activo en la gestión de su propia salud "as a result of a patient empowerment process within the healthcare system facilitated by means of a wide range of empowerment tools" (Askehave \& Zethsen 2010: 105). Entre dichas herramientas, parecen haber adquirido especial relevancia las medidas políticas adoptadas con el objetivo de que "people can participate in an informed way in the management of their own health" (Hall 2006: 271). Es decir, se trata de medidas dirigidas específicamente a garantizar el acceso a información relevante y adecuada sobre tratamientos, medicación y procedimientos quirúrgicos por parte de los pacientes. Con respecto a la adopción de este tipo de medidas de índole política y administrativa, argumentan Connor et al. (2008: 117) que "the degree to which a patient comprehends written messages related 
to prescription medications may be an important factor influencing patients' adherence to directives about medication use".

Así pues, se observa una toma de conciencia en torno a los problemas de legibilidad y facilidad de uso de los textos de divulgación médica en general y de los prospectos en particular, si bien parece que tal y como señalaban Askehave \& Zethsen (2002: 15) "in spite of all the intentions, complex and ambiguous texts still abound in expert writing for the general public", entre ellos, los prospectos. Hasta el día de hoy, esta afirmación no ha sido rebatida de manera contundente y definitiva, y abre la puerta al planteamiento de nuevas perspectivas de abordaje y análisis de los posibles factores que influyen en este hecho. Para ello, es necesaria la revisión previa de los aspectos determinantes del prospecto desde su triple consideración como: a) objeto de armonización jurídica, b) género y c) objeto de traducción.

\subsection{El prospecto como objeto de armonización jurídica}

En territorio de la Unión Europea, los medicamentos se comercializan acompañados de un documento estandarizado, cuya producción y distribución está regulada en el marco de legislación europea, a la cual están sujetos todos los estados miembros. Concretamente, las autoridades europeas han legislado esta materia en forma de directivas (Directiva 2001/83/CE y Directiva 2004/27/ $\mathrm{CE}$ ), un instrumento legislativo mediante el que se establecen únicamente los objetivos que cada país debe alcanzar, dejando en manos de las autoridades nacionales la elección de la herramienta legislativa que regulará el modo en que lo harán. A ello hay que añadir la creación del llamado Working Group on Quality Review of Documents ( $Q R D$ ), en el seno de la Agencia Europea del Medicamento, cuya misión es comprobar, promover y garantizar la claridad y legibilidad de los prospectos, para lo cual publicó en 2014 una serie de directrices básicas bajo el título Compilation of QRD decisions on stylistic matters in product information.

Con el fin de garantizar la inclusión de toda la información legalmente obligatoria en el lugar adecuado y mediante un tipo de lenguaje adaptado a las necesidades del paciente, los estados miembros y la Agencia Europea del Medicamento acordaron también la elaboración de una herramienta para la revisión de la calidad de los documentos que permitiera armonizar el modelo y que se tradujo en la publicación de unas plantillas bajo el nombre de Quality Review of Documents ( $Q R D)$ templates. Se trata de unas plantillas creadas también por el QRD de acuerdo con la legislación vigente y los parámetros lingüísticos establecidos en el documento elaborado por el Comité Farmacéutico 
de la Comisión Europea (2009) bajo el título Guideline on the Readability of the Labelling and Package Leaflet of Medicinal Products for Human Use

España, como país miembro de la Unión Europea, adoptó las directrices incluidas en las directivas antes aludidas y puso en marcha iniciativas orientadas a garantizar su cumplimiento, como la publicación en 2004 de un documento titulado Plan Estratégico de Política Farmacéutica y la designación del Comité Técnico de Información de la Agencia Española de Medicamentos y Productos Sanitarios, AEMPS, como responsable de la fijación de nuevos criterios que permitan garantizar la mejora de la comprensión de los prospectos. Dicho organismo basaba la falta de comprensión en el hecho de que "en muchas ocasiones la información es excesiva, ininteligible o inadecuada", en consonancia parcial con la Asociación Española de Derecho Farmacéutico, ASEDEF, en cuyo documento publicado en 2007, bajo el título La redacción del prospecto: recomendaciones para mejorar su comprensión, apuntaba a factores como el empleo de términos científicos, abreviaturas, ausencia de dibujos aclaratorios o información en algunos apartados, así como falta de actualización de información, entre otros.

Además, tanto la obligatoriedad de incluir un prospecto acompañando a cada medicamento, como las exigencias a las que están sujetos los productores con respecto a su formato y contenido son, a día de hoy, el resultado de cambios introducidos en la legislación europea, hasta tal punto que la autoridad competente puede llegar a rechazar una solicitud de autorización si la información contenida en el prospecto o, en su defecto, en el envase, no se ajusta a lo dispuesto en la normativa establecida para tal fin. En resumen, el prospecto está sujeto a una serie de requisitos legales que determinan en gran medida su formato y contenido y que, en última instancia, influyen también en su grado de comprensión.

\subsection{El prospecto como género}

El prospecto se concibe como género o "forma convencionalizada de texto que posee una función específica en la cultura en la que se inscribe y refleja un propósito del emisor previsible por parte del receptor" (cf. García Izquierdo 2002: 3). El grupo GENTT ha establecido una clasificación de los géneros médicos. El primer nivel clasificatorio lo constituye la categoría de macrogénero; el segundo nivel, el género; y el tercero, si procede, el subgénero. De acuerdo con ello, el género prospecto de medicamento se incluiría bajo el paraguas del macrogénero textos clínicos y carece de manifestaciones concretas en forma de subgénero (cf. García-Izquierdo 2009: 129-133). 
Por su parte, Askehave \& Zethsen (2003) analizaron detenidamente la situación comunicativa en la que se crean y utilizan los prospectos y los elementos que intervienen en ella y los categorizaron dentro de lo que denominaron como comunicación pública "that occurs when a company or an organization communicates with the general public" (cf. Askehave y Zethsen 2003: 23), que engloba géneros caracterizados por su distribución y recepción a gran escala, dirigidos a un público heterogéneo, en los que la relación entre emisor y receptor es asimétrica, la interacción entre ambos es impersonal, anónima y controlada por el emisor, la comunicación entre los anteriores se produce a través del género en cuestión que a su vez ha sido creado de acuerdo con los requisitos establecidos en uno o varios documentos de tipo legislativo y cuya función es prescriptiva.

En referencia específica a los prospectos, Gamero Pérez (2001: 82) les atribuye una doble función, expositiva y exhortativa, "por el hecho de que está dirigido al mismo tiempo al médico (a quien interesa sobre todo la descripción científica del producto) y al paciente (a quien interesa saber cómo administrarse el medicamento y qué precauciones tomar)". De igual modo, García Izquierdo (2008: 2) lo concibe como un género "predominantemente instructivo con elementos expositivos orientado al paciente y utilizado como puente entre este y la comunidad farmacéutica, entendida como los laboratorios fabricantes y comercializadores del medicamento y las instituciones que regulan esa fabricación y comercialización". Por su parte, Montalt i Resurrecció \& González Davies (2007: 57) clasificaron los géneros en el ámbito de la medicina en función de dos parámetros: el propósito retórico global del emisor (que en el caso de los prospectos sería el instructivo) y la función social global del texto (que en el mismo caso correspondería a la realización de actividades domésticas habituales como seguir una dieta o un tratamiento).

En el presente trabajo se comparte la idea de la doble función de los prospectos; sin embargo, la distinción entre dos tipos de destinatarios señalada por Gamero Pérez (2001) entraría en contradicción con la asimetría entre el emisor y el receptor que caracterizaría a los prospectos como un tipo de comunicación pública. Además, como señala Mercado López (2003a: 83):

[...] el emisor del prospecto es un profesional sanitario, específicamente un director técnico o médico de un laboratorio farmacéutico. El receptor del mensaje es el consumidor o usuario. Los profesionales sanitarios, por su parte, poseen otro tipo de texto para consulta, la ficha técnica, de carácter más especializado que el prospecto por lo que descartamos que sea esta comunidad discursiva el receptor principal. 
En resumen, el prospecto como género constituye el canal por el que la comunidad farmacéutica (emisor) transmite un mensaje con la finalidad de informar e instruir al paciente (destinatario) sobre el uso seguro de un producto farmacéutico y el modo de obtener el mayor beneficio de este o cómo tomar un medicamento de manera correcta, eficaz y segura.

\subsection{El prospecto como objeto de traducción intergenérica e intralingüistica}

En la Unión Europea, en función del territorio para el que se solicita y la posesión o no de autorización previa en algún país miembro, se distinguen cuatro posibles procedimientos de autorización de comercialización de los medicamentos y de su correspondiente prospecto: el nacional, el de reconocimiento mutuo, el descentralizado y el centralizado. Este último es el que nos interesa especialmente, ya que el proyecto de prospecto que se presenta ante la Agencia Europea del Medicamento junto con la solicitud de autorización de comercialización está originalmente redactado en inglés y, una vez aprobada su autorización, ha de traducirse a las 23 lenguas oficiales de la Unión Europea.

Si bien en el apartado 4 clasificamos y describimos los trabajos realizados en torno a diversos aspectos del prospecto como género, en este punto destacamos los trabajos de Montalt i Resurrecció y García Izquierdo (2013) y de Askehave y Zethsen (2000) por la inclusión de conceptos como traducción intergenércia e intralingüistica en relación con el prospecto y otros textos de divulgación médica. Concretamente, Askehave y Zethsen (2002) apuntan a dos factores determinantes como posibles causas de la existencia de prospectos en la UE que, a pesar de las medidas adoptadas, no cumplen con éxito sus objetivos comunicativos. Dichos factores están relacionados con la traducción: a) la traducción intergenérica, que tiene lugar cuando se extrae y transfiere la información de la ficha técnica al prospecto; aquí conciben el concepto de traducción en un sentido distinto al tradicional de una lengua a otra, sino de un género a otro; b) la traducción interlingüistica, en el sentido tradicional de traducción entre lenguas, cuando el borrador de prospecto en inglés se traduce a otras lenguas.

Por tanto, la traducción intergenérica que se lleva a cabo en el proceso de producción es un factor determinante para la legibilidad y facilidad de uso de los prospectos, ya que conlleva la selección de la información relevante para el receptor no especialista y su transferencia a un documento perteneciente a un género distinto utilizando un lenguaje adecuado a dicho receptor. A este se añade un factor determinante adicional en el caso de los prospectos que, con posterioridad, se deben someter al proceso de traducción interlingüística. 


\section{Estudios previos sobre el prospecto como género}

Las investigaciones realizadas en torno a los prospectos en las últimas dos décadas se han servido tanto de metodologías cuantitativas como cualitativas. Así, la aplicación de una metodología cuantitativa se basa en el empleo de fórmulas de legibilidad como herramienta de evaluación de géneros médicos destinados al público general (cf. Hedman 2008, Hardwood y Harrison 2004, Buchbinder et al. 2001, Ley y Florio 1996) y de los prospectos (cf. Ballesteros Peña y Fernández Aedo 2013,Barrio Cantalejo et al. 2008a/b, Mottram y Reed 1997). La aplicación de estas ecuaciones matemáticas arroja una puntuación que corresponde a una previsión estadística del grado de alfabetización que debe tener un lector medio para ser capaz de leer y comprender documentos relacionados con la salud. Hay una variedad de fórmulas (cf. Dale-Chall, FleschKincaid, índice SMOG y FOG, índice de Flesch-Szigriszt, Escala INFLESZ) fácilmente aplicables, si bien su validez y utilidad como única herramienta de análisis ha sido puesta en entredicho por algunos autores. No obstante, es posible encontrar estudios híbridos que combinan la aplicación de fórmulas de legibilidad con otros métodos, como la realización de entrevistas y grupos focales (cf. March Cerdá, 2010). También se han publicado trabajos dirigidos a la obtención y cuantificación estadística de datos en torno a la presencia o no de determinados elementos terminológicos (cf. Delaere et al. 2009, Hoste et al. 2008, 2010).

En el caso de la metodología cualitativa, es posible distinguir dos posibles aproximaciones aplicadas a los textos relacionados con la salud en general y los prospectos en particular. Por un lado, los llamados estudios de recepción, también conocidos como estudios de validación por parte del usuario (en inglés, consumer-tests o user-tests), son estudios de carácter empírico centrados en la obtención de datos relativos a la percepción y/o satisfacción de los usuarios con los prospectos mediante la aplicación de distintas estrategias investigadoras como entrevistas (cf. Connor et al. 2010, Barber et al. 2009, Wolf et al. 2007), grupos focales (cf. Dickinson et al. 2013; Raynor et al. 2004, Koo, Krass y Aslani 2002), cuestionarios (cf. Pander Maat y Lentz 2010, Clerehan et al. 2009, Berry et al. 2004, Berry, Michas y Bersellini 2003, Dickinson, Raynor y Duman 2001); o incluso una combinación de los tres (cf. Jensen 2013, Hirsh et al. 2009). Se trata, pues, de estudios que ponen el foco de atención en los resultados, ya que los datos analizados permiten describir el efecto producido por un texto en el lector (grado de comprensión, satisfacción y percepción con respecto a su usabilidad para el propósito perseguido). 
Por otro lado, dentro de la metodología cualitativa destacan también los estudios textuales, que permiten estudiar y evaluar cualitativamente los prospectos mediante el análisis de sus elementos textuales, lingüísticos, estilísticos o gráficos y que puede realizarse desde diferentes enfoques: a) la traductología (cf. Askehave y Zethsen2000a, 2002, 2003, 2006, 2008; Cacchiani 2006); b) la lingüística funcional sistémica (cf. Clerehan, Hirsh y Buchbinder 2009, Clerehan y Buchbinder 2006, Clerehan, Buchbinder y Moodie 2005, Hirsh et al. 2009); c) el análisis del discurso (cf. Fage-Butler 201la, 2011b; Askehave y Zethsen 2010; Connor et al. 2008; Dixon-Woods 2001).

\subsection{Estudios sobre el prospecto como género en España}

En España es posible clasificar los estudios realizados en esta materia en dos grupos en función de los investigadores involucrados y los objetivos perseguidos: a) los realizados por investigadores vinculados al mundo de la traducción, la mayoría centrados en el análisis contrastivo de un corpus paralelo inglésespañol a partir del enfoque de la lingüística funcional sistémica (cf. Martí Ferriol 2016; García Izquierdo 2008; Mercado López 2003a, 2003b, 2004; Ruiz Garrido et al. 2006; Ruiz Garrido, Fortanet Gómez y Palmer Silveira 2008; Vázquez y del Árbol 2013, 2014); b) los llevados a cabo por profesionales del ámbito biosanitario, cuyo principal objetivo es determinar la legibilidad lingüística de un corpus en español analizándolo mediante la aplicación de fórmulas de legibilidad (cf. Ballesteros Peña y Fernández Aedo 2013, March Cerdá et al. 2010, Barrio Cantalejo et al. 2008 a/b).

Por su relevancia destacamos el estudio llevado a cabo por Barrio Cantalejo et al. (2008), que analizaron la legibilidad gramatical de 55 prospectos de medicamentos mediante la aplicación del denominado Índice de Flesch (fórmula matemática que divide en 7 tramos una escala de 0 a 100 puntos para determinar el grado de legibilidad de un texto). Por otra parte, el trabajo de March Cerdá et al. (2009) presenta la particularidad de combinar métodos de investigación cualitativa (entrevista semiestructurada y grupo focal) y cuantitativa (fórmula de legibilidad). Por último, Ballesteros Peña y Fernández Aedo (2013) analizaron la legibilidad lingüística de un corpus compuesto por los prospectos de los 30 medicamentos más dispensados en España mediante la aplicación del índice de la aplicación informática denominada INFLESZ 1.0, que permite evaluar la legibilidad de un texto escrito en español según el Îndice de Legibilidad de Flesch-Szigriszt (IFSZ). 


\section{Criterios de selección del corpus}

En los estudios sobre el prospecto realizados con corpus en España arriba mencionados, la selección de los textos que componen su corpus se realizó en función de tres criterios: a) enfermedades más comunes en un rango determinado de edad y; b) traducciones $u$ originales en inglés y en español (cf. Ruiz Garrido, Palmer Silveira y Fortanet Gómez 2008; García-Izquierdo 2007; Mercado López 2003b, 2004); mientras que otros se han decantado por c) medicamentos más vendidos (cf. Vázquez y del Árbol 2013, 2014; Ballesteros Peña y Fernández Aedo 2013; Barrio Cantalejo et al. 2008a/b; March Cerdá et al. 2010).

El corpus analizado en el presente estudio está compuesto por dos subcorpus de textos paralelos, monolingües (en español), textual y cerrado. En la selección de los prospectos que los componen, se aplicaron básicamente dos criterios: a) la fuente; y b) la lengua. Es decir, se analizaron prospectos autorizados y publicados bien por la Agencia Europea del Medicamento (subcorpus de traducciones al español), bien por la Agencia Española de Medicamentos y Productos Sanitarios (subcorpus de originales en español). La selección de estos dos organismos como fuente de datos está justificada por los siguientes motivos: a) el acceso al texto completo a través de Internet en una página web oficial y fiable; b) la posibilidad de descargar un número elevado de documentos; c) la disponibilidad de prospectos en español (traducidos en el caso de la EMA y originales en el caso de la AEMPS); d) la disponibilidad de prospectos sometidos a un procedimiento de autorización similar y, por tanto, sujetos a una serie de requisitos legales.

Asimismo, optamos por no incluir en el corpus los medicamentos de uso hospitalario, ya que en esos casos el paciente no suele tener acceso al prospecto antes de su administración, que está sujeta al criterio casi exclusivo de los profesionales sanitarios. Del mismo modo que ocurre en el caso de las vacunas, cuya administración suele estar establecida en un calendario fijado por las autoridades sanitarias y, salvo en los casos en que hay que adquirirla en una farmacia por no estar incluida en la cobertura del sistema sanitario, el paciente no tiene acceso al prospecto antes de su administración. Aunque puede obtenerse el prospecto a través de otras vías (como las páginas web de las que hemos extraído nuestro corpus) no son documentos a los que cualquier persona tiene acceso en todos los casos, sino que deben darse otras variables (disponibilidad y capacidad de uso de Internet o disposición del profesional sanitario a entregarlo en caso de encontrarse ingresado).

La principal desventaja de recurrir a estos criterios es la falta de control de dos variables: el proceso y los responsables de la elaboración de los documentos. 
Ahora bien, el control de dichas variables no es necesario para alcanzar los objetivos del presente trabajo, ya que estos se centran en la detección e identificación de determinados elementos que influyen en la legibilidad de los prospectos, no en la búsqueda de los motivos que pudieran ser parcial o totalmente responsables de ellos en el caso de que se dieran. Una vez escogidas las fuentes fue necesario aplicar criterios adicionales de selección para dar coherencia al corpus en función del objetivo perseguido. Así, se seleccionaron únicamente los prospectos autorizados, aunque de entre ellos se excluyó los sometidos a seguimiento adicional y los que acompañan a medicamentos de uso hospitalario y a vacunas. Asimismo, con el fin de garantizar que los prospectos que componían el corpus constaban de los mismos apartados, se decidió seleccionar únicamente los referidos a medicamentos cuya forma farmacéutica fueran los comprimidos, cuya administración es sencilla y no necesita explicaciones o aclaraciones adicionales.

Tras la aplicación de los criterios anteriores se decidió fijar un límite y establecer una cantidad de textos suficientemente representativa del estado de la lengua específicamente seleccionada, a la par que abarcable, teniendo en cuenta las limitaciones espacio-temporales de nuestra investigación. Tomando todo esto en consideración, además de las características y el tamaño de los corpus estudiados en otros trabajos anteriores de similares características, se estimó que la inclusión aleatoria (tras la preselección) de 150 textos, 75 originales (corpus AEMPS) y 75 traducciones (corpus EMA), era representativo y pertinente para alcanzar el objetivo investigador.

\section{Metodología de análisis}

Como ya se ha señalado anteriormente, en el presente artículo el foco de atención se sitúa en la legibilidad en relación con la capacidad divulgativa (de transmitir información de manera clara y comprensible para el lector lego) de los prospectos y con su traducción; de ahí que su análisis se aborde desde un punto de vista comunicativo. Concretamente el objetivo perseguido es determinar si el proceso de traducción puede influir en el grado de legibilidad en los textos traducidos frente a los originales. Para alcanzar dicho objetivo se analizó el corpus antes descrito (textos traducidos y originales por separado) mediante la aplicación de una fórmula matemática de legibilidad gramatical denominada Escala INFLESZ, que permite obtener datos cuantitativos comparables en un análisis cualitativo posterior, con el fin de establecer diferencias o similitudes en el grado de legibilidad traducciones y originales en español.

Tanto esta fórmula como otras, ya sea la Escala RES de Flesch, el SMOG, la Flesch-Kincaid, el Gunning FOG testo el Gráfico de Fry, basan su análisis en 
el supuesto de que los textos con más palabras y frases cortas son más fáciles de leer y sirven y se emplean para establecer la correlación matemática entre el tamaño de las palabras y frases y su facilidad de lectura. Concretamente, la Escala RES de Flesch divide en 7 tramos una escala de 0 a 100 puntos. La dificultad media de un texto se sitúa entre 60 y 70; por debajo se considera difícil de leer y más fácil cuanto más alta sea la puntuación entre 70 y 100. En España, el pedagogo Fernández-Huerta la adaptó por primera vez en 1959 al español, rebautizándola como 'fórmula de lecturabilidad' y asociando cada tramo de la escala de interpretación a un nivel académico determinado.

\begin{tabular}{|l|l|l|}
\hline LECTURABILIDAD & \multicolumn{1}{|c|}{ NIVEL } & \multicolumn{1}{c|}{ GRADO } \\
\hline $90-100$ & MUY FÁCIL & APTO PARA EL 4 GRADO \\
\hline $80-90$ & FÁCIL & APTO PARA EL 5 GRADO \\
\hline $70-80$ & BASTANTE FÁCIL & APTO PARA EL 6 $6^{\circ}$ GRADO \\
\hline $60-70$ & NORMAL & APTO PARA EL $7^{\circ}$ Y $8^{\circ}$ GRADO \\
\hline $50-60$ & BASTANTE DIFÍCIL & PREUNIVERSITARIO \\
\hline $30-50$ & DIFÍCIL & CURSOS SELECTIVOS \\
\hline $0-30$ & MUY DIFÍCIL & UNIVERSITARIO (ESPECIALIZACIÓN) \\
\hline
\end{tabular}

Figura 1: Grados de dificultad de los textos en español según el índice Fernández-Huerta

En 1992, en su tesis doctoral, Szigriszt Pazos validó y adaptó la fórmula Flesch (Flesch Reading Ease Formula) para su aplicación a textos en español, dando como resultado el índice de legibilidad de Flesch-Szigriszt (IFSZ) o 'fórmula de perspicuidad'. Para ello modificó las constantes de la escala de interpretación de Flesch, a la que llamó 'escala de nivel de perspicuidad'. Según esta, un texto tiene una legibilidad normal cuando tiene puntuaciones entre 50 y 65 y se irá haciendo más difícil según se aproxime a los tramos cercanos a 0 , donde se sitúa la literatura científica, técnica o filosófica.

Posteriormente, Barrio Cantalejo et al. (2008b) atribuyeron cierta falta de consistencia a la fórmula de perspicuidad, al considerar que la muestra de textos que utilizó Szigriszt Pazos no era representativa, ni se seleccionó aleatoriamente. Para solventarlo establecieron el índice INFLESZ, resultado de la combinación del índice Flesch-Szigriszt y la escala Inflesz, que establece cinco grados de dificultad para los textos en español, como muestra la siguiente figura: 


\begin{tabular}{|l|l|l|}
\hline PUNTOS & \multicolumn{1}{|c|}{ GRADO } & \multicolumn{1}{c|}{ TIPO DE PUBLICACIÓN } \\
\hline$<40$ & MUY DIFÍCIL & Universitario, científico \\
\hline $40-55$ & ALGO DIFÍCIL & $\begin{array}{l}\text { Bachillerato, divulgación científica, prensa } \\
\text { especializada }\end{array}$ \\
\hline $55-65$ & NORMAL & E.S.O. prensa general, prensa deportiva \\
\hline $65-80$ & $\begin{array}{l}\text { BASTANTE } \\
\text { FÁCIL }\end{array}$ & $\begin{array}{l}\text { Educación primaria, prensa del corazón, novelas de } \\
\text { éxito }\end{array}$ \\
\hline$>80$ & MUY FÁCIL & Educación primaria, tebeos cómic \\
\hline
\end{tabular}

Figura 2: Grados de dificultad de los textos en español según la escala INFLESZ

El cálculo del índice INFLESZ se puede realizar de manera automática mediante la aplicación del software INFLESZ 1.0, de libre distribución. La posibilidad de analizar un corpus electrónico, el hecho de que el principal motivo de su concepción fuera el interés por contar con una herramienta fiable de análisis de la legibilidad de los textos dirigidos a pacientes y su validación posterior precisamente con prospectos, fueron determinantes para su elección como herramienta de análisis en la primera fase. A continuación, se detalla cada una de las variables que el sofware INFLESZ 1.0 permite evaluar en los textos escritos en español, a saber: palabras, sílabas, frases, promedio sílabas/ palabra, promedio palabras/frase, Índice Flesch-Szigriszt (la fórmula aplicada es: 206,835 - (62,3 x S/P) - P/F, donde P es el número de palabras del texto activo, $\mathrm{S}$ el número de sílabas y $\mathrm{F}$ el número de frases); Grado en la Escala Inflesz (resultado de la combinación del índice Flesch-Szigriszt y la Escala Inflesz), correlación Word: resultado de la inclusión de la fórmula Flesch entre las utilidades de Microsoft Word, índice Fernández-Huerta (su fórmula es: 206,84-(60 x (S / P)) - (1,02 x (P / F), donde S es el número de sílabas, P el número de palabras y $\mathrm{F}$ el número de frases).

Gracias a la aplicación del software INFLESZ para el análisis de cada uno de los textos que componen nuestro corpus obtuvimos datos claramente cuantificables en relación a su grado de legibilidad. A continuación, se presentan y describen los más destacados en virtud del objetivo perseguido. 


\section{Resultados}

7.1 Resultados cuantitativos de la aplicación de INFLESZ 1.0

La longitud de las frases es una de las variables empleadas para medir el grado de legibilidad de los textos. Tanto la Comisión Europea (2009) (en referencia a los prospectos) como Askehave y Zethsen (2006) (con respecto a la comunicación experto-lego, en general), recomiendan evitar el empleo de oraciones largas y complicadas (no solo por su longitud, sino también por el léxico y estructuras contenidas). Para facilitar la visualización de los datos extraídos con respecto a esta variable, se agruparon los resultados en 7 rangos con una diferencia de 50 frases, siendo el primero el de los textos con menos de 150 frases y el último el de los que superan las 400 . Tal y como queda reflejado en el siguiente gráfico:

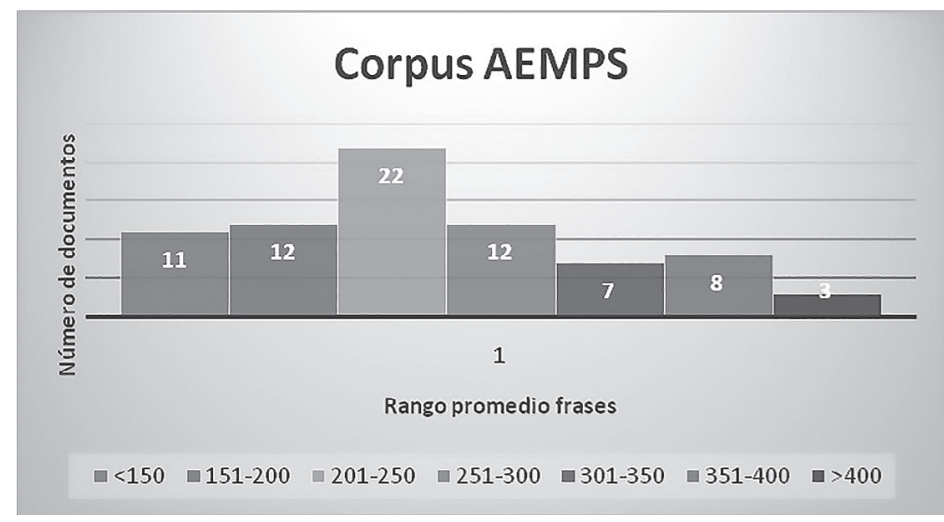

Figura 3: Promedio de frases (AEMPS)

En el corpus AEMPS los textos se reparten en los 7 rangos establecidos de manera bastante equitativa. Marcan especialmente la diferencia el grupo referido a los textos compuestos por entre 201 y 250 frases de media, con 22 documentos $(29,33 \%)$ y el de los que tienen un promedio inferior a 150 , con solo 2 textos. Le siguen otros dos rangos con 12 documentos cada uno, correspondientes a los que tienen un promedio de frases de 151-200 y 251-300 respectivamente y otro que incluye 11 documentos con menos de 150 frases de media; en el lado opuesto se sitúa un grupo de 8 documentos con 351-400 frases de media y otro de 7 documentos con un promedio de 301-350 frases. Solo 3 (4\%) superan las 400 palabras. 


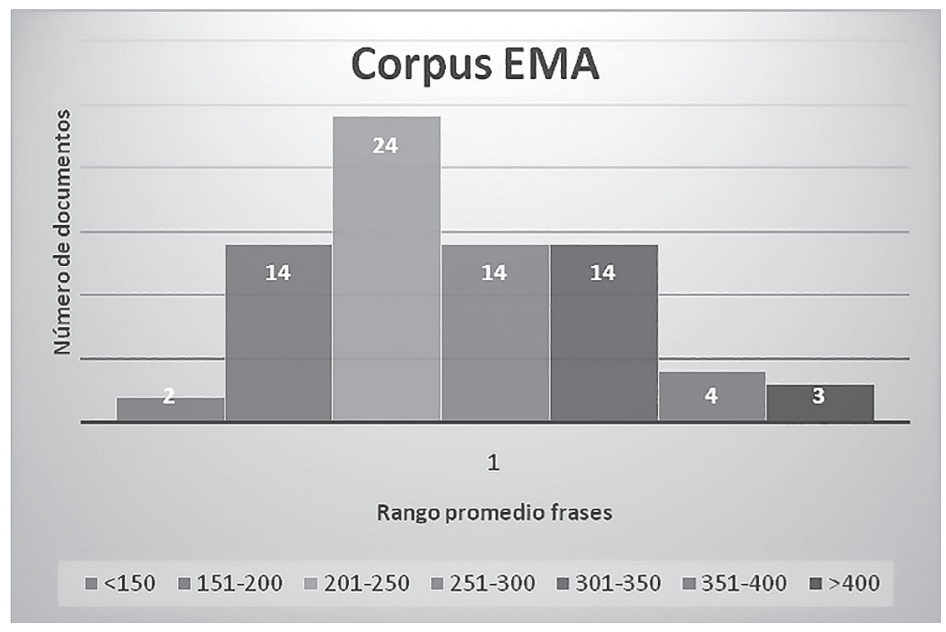

Figura 4: Promedio de frases (EMA)

Entre los prospectos aprobados a través de la EMA también destaca el grupo compuesto por 24 documentos (32\%) que tienen entre 201 y 250 frases de media. Le siguen otros tres grupos, con 14 documentos cada uno, cuyos documentos contienen un promedio de 151-200, 251-300 y 301-350 frases respectivamente. Les siguen 4 documentos con un promedio de 351-400 frases y 3 con más de 400 frases de media. Solo 2 textos tienen menos de 150 frases de media.

El promedio de palabras por frase es también determinante en el establecimiento del grado de legibilidad de los textos. De hecho, una de las recomendaciones de la Comisión Europea (2009) es la disposición y organización de la información en párrafos y epígrafes cortos (efectos adversos, síntomas, etc.). Tradicionalmente, los textos originales en español (especialmente lego-lego y experto-lego) están compuestos por oraciones y párrafos largos repletos de oraciones subordinadas y aposiciones, frente al inglés, cuyas estructuras sintácticas suelen ser más sencillas y cortas en general. Aunque en menor medida, esta tendencia al uso de oraciones largas y sintácticamente complicadas suele mantenerse incluso en el ámbito de la ciencia y la tecnología, cuyas convenciones textuales establecen (sobre todo en los textos expertoexperto) el uso de frases más cortas que garanticen la precisión y objetividad propia de la información que trasladan.

El análisis de los prospectos del corpus arroja unos datos con respecto al promedio palabras/frase que hemos agrupado en rangos diferenciados por 10 palabras. La siguiente figura muestra los resultados del corpus AEMPS: 


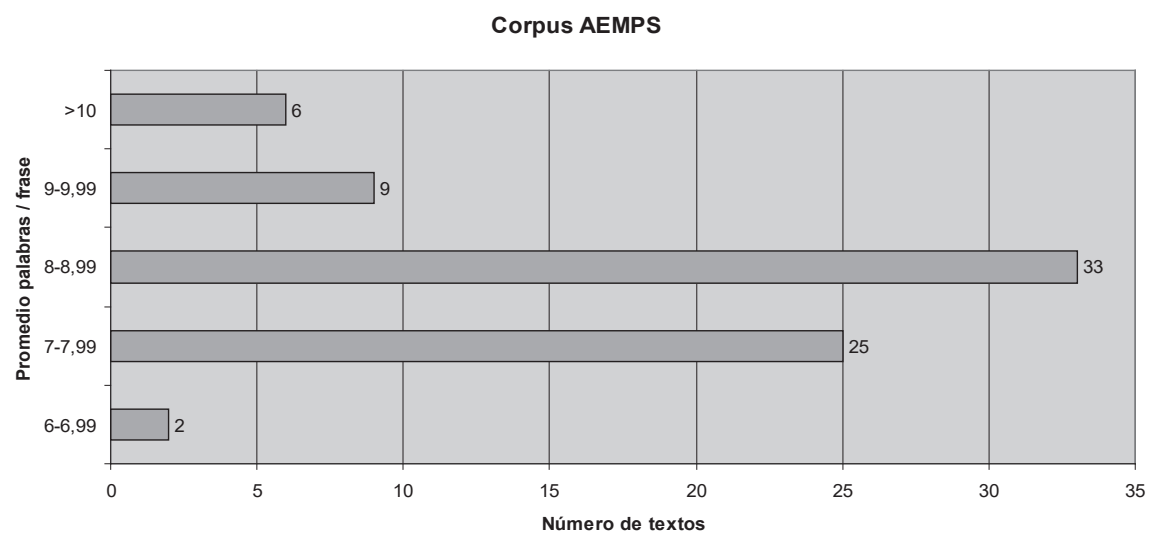

Figura 5: Promedio palabras/frase (AEMPS)

La mayor parte de los prospectos del corpus AEMPS tienen un promedio de entre 7 y 9 palabras por frase; concretamente 33 (44\%) tienen entre 8 y 8,99 y 25 (33,33\%) entre 7 y 7,99. A distancia le siguen los 9 (12\%) documentos que tienen una media de 9 a 9,99 palabras por frase y los 6 que tienen entre 9 y 9,99. Únicamente 2 están compuestos por frases con promedio de 6 a 6,99 palabras/frase.

En el caso de los prospectos del corpus EMA destacan especialmente los 41 documentos $(54,6 \%)$ cuyas frases tienen entre 8 y 8,99 palabras/frase de media, seguidos de lejos por los 17 (22,6\%) cuyo promedio va de 7 a 7,99. También disminuye el grupo que tiene de 7 a 7,99 palabras/frase de media con 11 documentos $(8,25 \%)$. Le sigue un grupo de 5 con un promedio superior a 10 palabras/frase y 1 solo con una media entre 6 y 6,99 en el lado opuesto, como muestra la figura a continuación: 


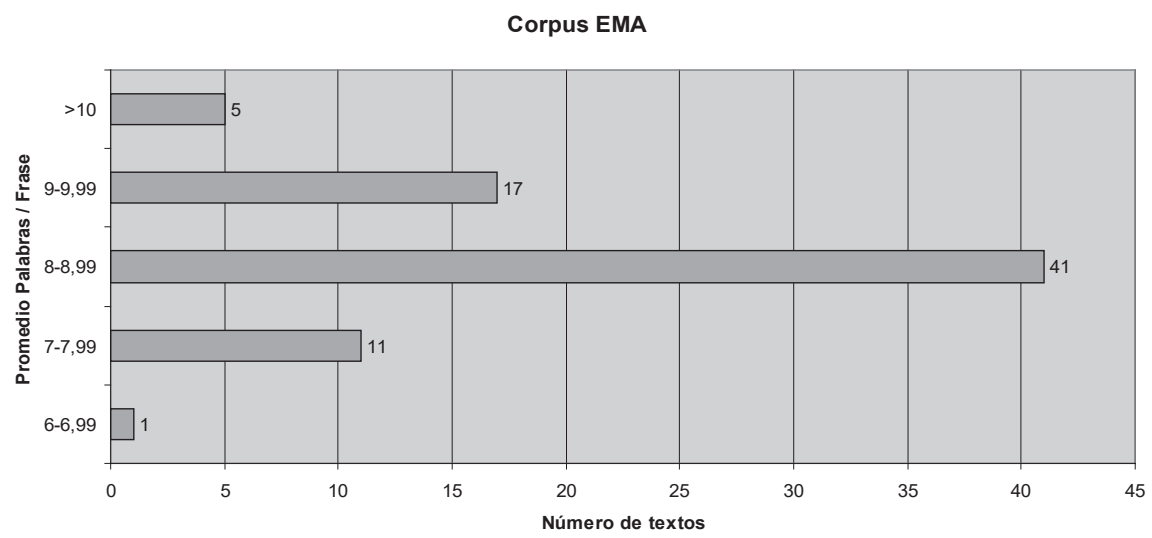

Figura 6: Promedio palabras/frase (EMA)

Recordemos que el grado Inflesz es el resultado de la combinación del índice Flesch-Szigriszt (cuya fórmula combina el número de palabras, sílabas y frases en el texto) y la escala Inflesz, que establece cinco grados de legibilidad para los textos en español. Los resultados del análisis de los prospectos de nuestro corpus mediante la aplicación de esta herramienta agrupan los textos de ambos subcorpus únicamente en dos grados en la Escala Inflesz, a saber: 'algo difícil', que corresponde a una puntuación entre 40-55 en el índice de Flesch-Szigriszt y 'normal', equivalente a 55-65 puntos en el mismo índice.

Ahora bien, los resultados del análisis de cada subcorpus son opuestos, ya que en el corpus EMA, el 70,6\% de los prospectos obtuvo una puntuación en el índice Flesch-Inflesz de entre 55 y 65, que corresponde al grado Infleszde legibilidad 'normal' y el resto obtiene entre 40 y 55 puntos, que corresponden a un grado de legibilidad 'algo difícil', tal y como queda reflejado en la siguiente figura: 


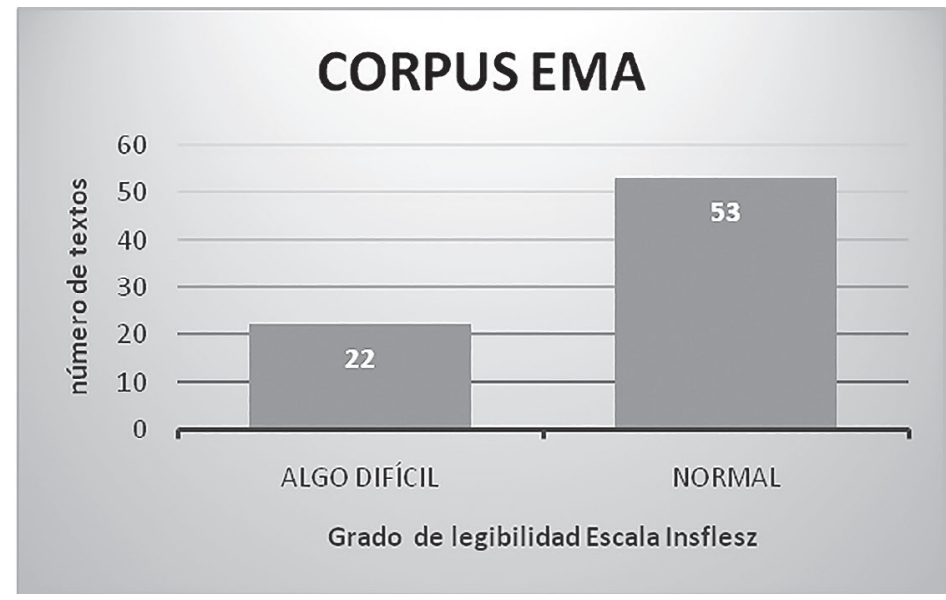

Figura 7: Grado Escala INFLESZ (EMA)

Por el contrario, 48 (el 64\%) de los prospectos del corpus AEMPS obtienen entre 40 y 55 puntos, es decir, poseen un grado 'algo difícil' de legibilidad en la escala Inflesz, frente a los 27 (36\%) cuyo grado de dificultad se considera 'normal' en la misma escala, como muestra la siguiente figura:

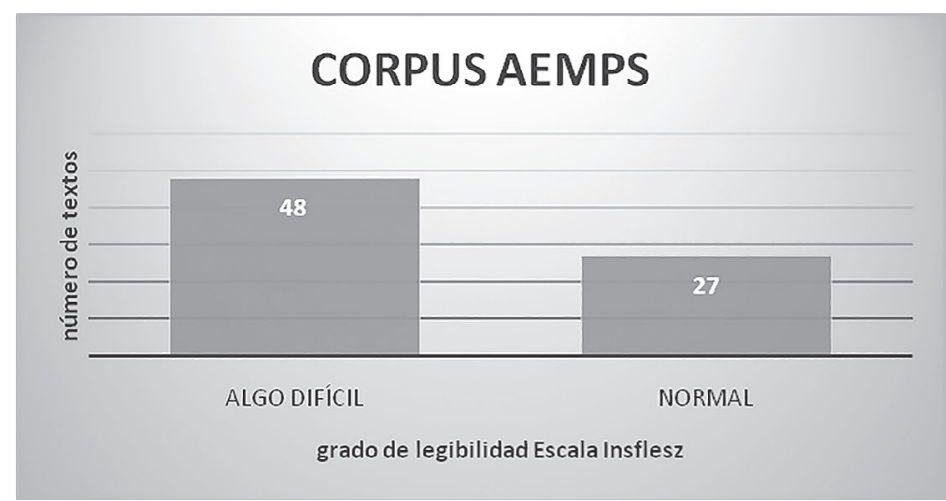

Figura 8: Grado Escala INFLESZ (AEMPS)

Los resultados obtenidos según el índice Fernández Huerta muestran casi plena coincidencia en el caso del corpus EMA, ya que 21 documentos se sitúan en el rango 'bastante difícil' (frente a 22 en la Escala Inflesz) y 54 en el 'normal' (frente a los 53 en la Escala Inflesz), tal y como muestra la figura: 


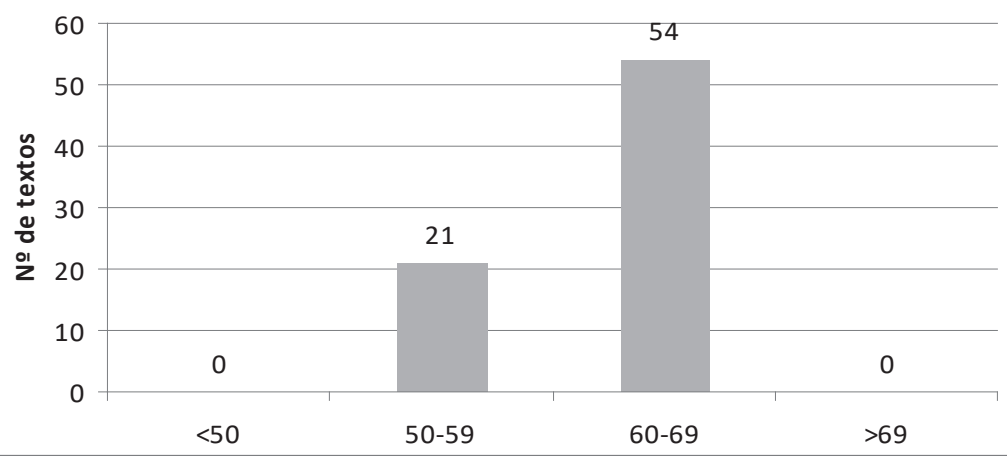

Figura 9: Índice Fernández-Huerta (EMA)

En el corpus AEMPS, 45 documentos obtienen un grado de legibilidad 'bastante difícil' y 27 'normal'. Además, 2 se consideran 'difíciles' y 1 'bastante fácil' en el índice Fernández Huerta.

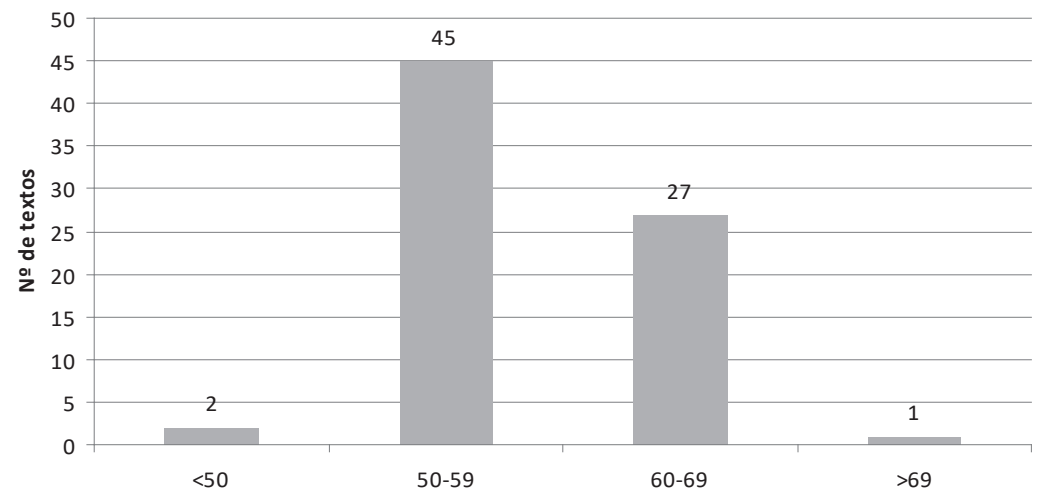

Figura 10: Índice Fernández-Huerta (AEMPS)

Una vez presentados los datos cuantitativos más destacados con respecto al análisis de la legibilidad de nuestro corpus, evaluaremos y comentaremos sus implicaciones desde una perspectiva cualitativa. 


\subsection{Análisis cualitativo de los datos cuantitativos}

En relación con el promedio de frases que componen los documentos de cada subcorpus, se observa claramente que en ambos casos, originales (AEMPS) y traducciones (EMA) al español, predominan los textos compuestos por una media de 201-250 frases (casi un tercio del total en ambos casos). Ahora bien, el número total de documentos que superan las 250 frases de media es algo mayor en el caso del corpus EMA, con 35 documentos $(46,66 \%)$, frente a los $30(40 \%)$ del corpus AEMPS. No obstante, se aprecia una diferencia más significativa en el caso de los que tienen menos de 250 frases de media, ya que solo 2 prospectos de la EMA $(2,66 \%)$ se incluyen en ese grupo frente a los 11 de la AEMPS (14,66\%). En general la mayor parte de los textos del corpus EMA se concentra en los rangos centrales ( 66 documentos, $88 \%$, con un promedio de 150 a 350 palabras). Sin embargo, en el caso de los del corpus AEMPS el reparto de documentos entre los 7 rangos es mucho más dispar y sin diferencias excesivamente significativas entre ellos. Esto indica que los documentos traducidos al español son más homogéneos en cuanto a la estructura y longitud de las frases empleadas, frente a los originales, que muestran más heterogeneidad y variedad en este aspecto.

El anterior dato contrasta con el que se refiere al promedio de palabras por frase, ya que este es más elevado entre los textos del corpus traducido (EMA), debido a que únicamente 12 documentos (16\%) tienen una media igual o inferior a 7,99 palabras/frase y el resto se sitúa por encima de esa cantidad; frente a ello, 27 de los prospectos del corpus original (36\%) están compuestos por frases cuya media de palabras se sitúa igual o por debajo de 7,99. En cuanto a los que superan esa cifra, 33 textos (44\%) tienen un promedio de entre 8 y 8,99 palabras por frase en el caso de la AEMPS, mientras que en el de la EMA la cantidad asciende a 41 documentos (54,6\%). Finalmente, destaca el hecho de que la cifra de textos que superan las 9 palabras/frase de media es superior en el caso del subcorpus EMA (17 textos, 22,66\%, entre 9 y 9,99 y 5 textos, $6,66 \%$, más de 10) que en el subcorpus AEMPS ( 9 textos, 12\%, entre 9 y 9,99 y 6 textos, $8 \%$, más de 10).

Así pues, resulta llamativo que los textos traducidos del inglés al español tengan, en general, un promedio de palabras/frase mayor que los originales, ya que los textos en español suelen contener frases más largas y sintácticamente complicadas que los textos originales en inglés, derivados de la identidad de la lengua y su propia sintaxis. Por tanto, lo lógico sería quelos textos traducidos desde el inglés al español estuvieran compuestos por frases no excesivamente largas y sin aparente complicación desde un punto de vista sintáctico, fruto de la transposición de estructuras del original. La búsqueda de una posible 
respuesta a esta cuestión nos lleva a pensar que quizás se debe al hecho de que los traductores introducen más elementos aclaratorios (como aposiciones o explicaciones) y son más conscientes de las posibles necesidades del receptor meta, que no posee un conocimiento científico de la materia. No obstante, sería necesario un análisis más específico que permitiera obtener datos que confirmaran o negaran esta hipótesis.

Por último, si se comparan los resultados obtenidos en relación con el grado de legibilidad en la Escala Inflesz, se observa un resultado opuesto entre uno y otro subcorpus, ya que el $64 \%$ de los prospectos originales obtienen un grado de legibilidad 'algo difícil' y el resto 'normal'; mientras que el 70,6\% de los traducidos se sitúan en un grado de legibilidad 'normal' y el resto 'algo difícil'. Llama la atención que los textos originales sean menos legibles que los traducidos. Cabe pensar que este resultado se deba a las variables que intervienen en el cálculo de ambos índices, Flesch-Szigriszt y Fernández-Huertas, a saber: número de sílabas, número de palabras y número de frases. Si se retoman los resultados anteriormente comentados con respecto al número de frases y el promedio de palabras por frase, podría concluirse que la justificación está en los números absolutos y no en los promedios, y que la dificultad radica más en las sílabas que componen las palabras que en la longitud de las frases que componen el texto. Este resultado, al igual que el anterior relacionado con el promedio de palabras/frase, nos lleva también a plantearnos la posible influencia de otras variables y elementos de naturaleza extratextual que podrían analizarse para la obtención de nuevos datos al respecto.

\section{Conclusiones}

Para concluir cabe señalar que los resultados cuantitativos obtenidos parecen demostrar que los prospectos originalmente redactados en español presentan más problemas de legibilidad que los traducidos. Este hecho podría deberse las convenciones propias del español en general y del lenguaje de las ciencias farmacéuticas en particular, plasmadas en el uso que de él hacen los redactores expertos en la materia. Estos cuentan con unos conocimientos conceptuales y metalingüísticos que les permiten garantizar la precisión y corrección de la información que transmiten, si bien sus competencias lingüísticas y comunicativas parecen estar más limitadas. Ahora bien, esto último es una hipótesis que habría de ser despejada en estudios posteriores que incluyan otras variables de análisis.

Asimismo, los resultados obtenidos parecen reflejar el impacto de la implementación y la aplicación de las medidas legislativas y recomendaciones puestas en marcha en los últimos años por las autoridades europeas y españolas. La 
aplicación de una plantilla como texto base y la recomendación del uso de epígrafes para evitar oraciones largas y complicadas podría haber tenido una cierta influencia en la reducción de la longitud y el número de frases empleadas en los prospectos originales en español.

A pesar de ello, índices de legibilidad como el Flesch-Szigriszt (que tiene en cuenta también otras variables, como el número de palabras, sílabas y frases), arrojan todavía resultados negativos con respecto a los prospectos originales, ya que predominan los textos con un grado 'algo difícil' de legibilidad. Frente a ellos, el análisis de los prospectos del corpus traducido arroja resultados más positivos, con un predominio de textos situados en un grado de legibilidad 'normal'.

Por lo tanto, a la pregunta de si el proceso de traducción inglés-español es, en general, un factor determinante en la elaboración de prospectos legibles cabe señalar que, en términos generales, la traducción parece no tener un impacto negativo en la legibilidad de los prospectos; sí que parece tener un impacto limitado, pero debido no tanto al proceso traductor en sí (ya que los traductores parecen contar con los conocimientos lingüísticos necesarios), sino al marco legislativo y a la diversidad de recomendaciones y patrones traductológicos a los que está sometido el proceso traductor paradójicamente en aras de garantizar dicha legibilidad.

Estos resultados nos hacen plantearnos nuevas hipótesis para cuya respuesta en futuras investigaciones sería necesaria la integración de variables adicionales de naturaleza extratextual. Concretamente, se trataría de un estudio de casos orientado hacia la descripción del marco profesional en el que se llevan a cabo tanto la redacción de los originales como la traducción de los que no lo son y que aportara información sobre las limitaciones y condiciones de trabajo a las que están sometidos tanto redactores como traductores en el desempeño de su actividad profesional diaria (además de las limitaciones legales que hemos mencionado). Igualmente sería interesante el diseño de algún tipo de estudio de recepción por parte de los potenciales destinatarios, ya sea en forma de grupo focal, entrevista, cuestionario etc., ya que pueden aportar datos complementarios y un punto de vista interesante en combinación con otras metodologías como la del presente trabajo.

\section{Referencias bibliográficas}

AskeHAVE, Inger \& Karen Korning Zethsen. (2000) "Inter-generic and Interlinguistic translation of patient package inserts." En: Mayer, Felix (ed.) 2000. Language for Special Purposes: Perspectives for the New Millennium. Tübingen: Gunter Narr, pp. 882-887. 
ASKEHAVE, Inger \& Karen Korning Zethsen. (2002) "Translating for laymen." Perspectives: Studies in Translatology 10:1, pp. 15-29.

ASKEHAVE, Inger \& Karen Korning Zethsen. (2003) "Communication barriers in public discourse: The patient package insert." Document Design 4:1, pp. 22-41.

ASKeHAVE, Inger \& Karen Korning Zethsen. (2006) "Medical communication: Professional-Lay." En: Brown, Keith. (ed.) 2006. Encyclopedia of Language $\mathcal{E}$ Linguistics. Oxford: Pergamon press, pp. 644-649.

ASKEHAVE, Inger \& Karen Korning Zethsen. (2008) "Mandatory Genres: The case of European Public Assessment Report (EPAR) summaries.” Text E Talk 28:2, pp. 167-191.

ASKEHAVE, Inger \& Karen Korning Zethsen. (2010) “'Check it out'- the construction of patient empowerment in health promotion leaflets.” En: Ruiz Garrido, Miguel Francisco; Juan Carlos Palmer Silveira \& Inmaculada Fortanet Gómez (eds.) 2010. English for Academic and Professional Purposes. Utrecht: Rodopi, pp. 105-119.

BAllesteros PeÑA, Sendoa \& Irrintzi Fernández Aedo. (2013) “Análisis de la legibilidad lingüística de los prospectos de los medicamentos mediante el índice de Flesch-Szigriszt y la escala Inflesz." Anales del Sistema Sanitario de Navarra 36:3, pp. 397-406. Versión electrónica: <http://scielo.isciii.es/scielo. php?pid=S1137-66272013000300005\&script=sci_arttext $>$

BARber, Melissa N.; Margaret Staples; Richard H. Osborne; Rosemary Clerehan; Catherine Elder \& Rachelle Buchbinder. (2009) "Up to a quarter of the population may have suboptimal health literacy depending upon the measurement tool: results from a population-based survey." Health Promotion International 24:3, pp. 252-261.

Barrio Cantalejo, Inés M.; Pablo Simón-Lorda; Joan Carles March Cerdá \& M. Ángeles Prieto Rodríguez. (2008a) "Legibilidad gramatical de los prospectos de los medicamentos de más consumo y facturación en España en 2005." Anales del Sistema Sanitario de Navarra 31:2, pp. 559-566. Versión electrónica: <http:// www.scielosp.org/pdf/resp/v82n5/original_breve.pdf>

BARRio CANTALEjO, Inés M.; Pablo Simón Lorda; Miguel Melguizo; Isabel Escalona; María Isabel Marijuán \& Pablo Hernando. (2008b) "Validación de la Escala Inflesz para evaluar la legibilidad de los textos dirigidos a pacientes." Revista Española de Salud Pública 82:5, pp. 135-152. Versión electrónica: <http://scielo. isciii.es/pdf/asisna/v31n2/original2.pdf>

BERRY, Dianne C.; Irene C. Michas \& Elisabetta Bersellini. (2003) "Communicating Information about Medication. The Benefits of Making it Personal." Psychology and Health 18:1, pp. 127-139.

BuCHBINDER, Rachel; Stephen Hall; Gail Grant; Arul Mylvaganam \& Mark R.Patrick. (2001) "Readability and content of supplementary written drug information 
for patients used by Australian rheumatologists." Medical Journal of Australia 174 , pp. 575-578.

CACCHIAni, Silvia. (2006) "Dis/Similarities between PILs in Britain and Italy: Implications for the Translator." New Voices in Translation Studies 2, pp. 28-43. Clerehan, Rosemary; Rachel Buchbinder \& Jane Moodie. (2005) "A linguistic framework for assessing the quality of written patient information: Its use in assessing methotrexate information for rheumatoid arthritis." Health Education Research 20:3, pp. 334-344.

ClEREHAN, Rosemary \& Rachel Buchbinder. (2006) "Toward a more valid account of functional text quality: The case of the patient information leaflet." Text $\&$ Talk 26:10, pp. 39-68.

Clerehan, Rosemary; Dianne Hirsh \& Rachel Buchbinder. (2009) "Medication information leaflets for patients: The further validation of an analytic linguistic framework." Communication E Medicine 6:2, pp. 117-127.

Connor, Ulla M.; Miguel F. Ruiz Garrido; William Rozycki; Elizabeth Goering; Eleanor D. Kinney \& Julia M. Koehler et al. (2008) "Patient-directed medicine labeling: Text differences between the United States and Spain." Communication E Medicine 5, pp. 117-132.

Connor, Ulla M.; Elizabeth M. Goering; Marianne S. Matthias \& Robert Mac Neill. (2010) "Information Use and Treatment Adherence among Patients with Diabetes." En Miguel F. Ruiz Garrido; Juan C. Palmer Silveira e Inmaculada Fortanet Gómez (eds.) 2010. English for Professional and Academic Purposes. Amsterdam \& New York: Rodopi, pp. 89-104.

Delaere, Isabelle; Veronique Hoste; Claudia Peersman; Leona Van Vaerenbergh \& Peter Velaerts. (2009) “ABOP, Automatic Optimization of PILs.” En: Proceedings of the International Symposium on Data and Sense Mining, Machine Translation and Controlled Languages. Besançon: Université de France-Compté, pp. 74-81.

DiCKINSON, Rebecca; Kim Hamrosi; Peter Knapp; Parisa Aslani; Julie Sowter; Ines Krass \& David K. Raynor. (2013) "Suits you? A qualitative study exploring preferences regarding the tailoring of consumer medicines information." International Journal of Pharmacy Practice 21:4, pp. 207-215.

DiCKInSON, David; D. K. Theo Raynor \& Mark Duman. (2001) "PILs for medicines: using consumer testing to determine the most effective design." Patient Education and Counseling 43:2, pp. 147-159.

DixON-WoODS, Mary. (2001) "Writing wrongs? An analysis of published discourses about the use of patient information leaflets." Social Science and Medicine 52 pp. 1417-1432.

DuBAY, William H. (2004) The principles of readability. Costa Mesa: Impact Information.

FAGE-Butler, Antoinette. (2011a) "The discursive construction of risk and trust in patient information leaflets." Hermes 46, pp. 61-74. 
FAGE-BUTLER, Antoinette. (2011b) Towards a new kind of patient information leaflet? Risk, trust and the value of patient centered communication. Aarhus: Aarhus University. Tesis doctoral.

GAL, Iddo \& Ayelet Prigat. (2004) "Why organizations continue to create patient information leaflets with readability and usability problems: an exploratory study." Health Education Research 20:4, pp. 485-493.

Gamero PÉrez, Silvia. (2001) La traducción de textos técnicos. Barcelona: Ariel.

GARCía IZQUIERDO, Isabel. (2002) "El género: plataforma de confluencia de nociones fundamentales en didáctica de la traducción." Revista Discursos. Estudos sobre traduçao 2, pp. 13-20. Versión electrónica: <https://repositorioaberto.uab.pt/bitstream/10400.2/4098/1/Isabel\%20Garcia\%20Izquierdo.pdf>

GARCÍA IZQUIERDO, Isabel. (2009) Divulgación médica y traducción: el género información para pacientes. Berna: Peter Lang.

GARCíA IZQUIERDO, Isabel \& Vicent Montalt i Resurrecció. (2009) "Equigeneric and Intergeneric Translation in Patient-Centred Care." Hermes 51, pp. 39-52.

García IZQUiERDO, Juan Manuel. (2008) "Estudio descriptivo del prospecto de medicamentos desde una perspective traductológica." En: Campos Pardillos, Miguel Ángel \& Adelina Gómez González-Jover (eds.) 2008. The Language of Health Care: Proceedings of the first International Conference on Language and Health Care, Alicante, 24-26 Octubre 2007.

GÖPFERICH, Susanne. (2009) "Comprehensibility assessment using the Karlsruhe Comprehensibility Concept." JoSTrans - The Journal of Specialised Translation 11, pp. 31-53. Versión electrónica: <http://www.jostrans.org/issue11/art_ goepferich.pdf>

Hall, David. R. (2006) "Medical leaflets, empowerment and disempowerment." En: Gotti, Maurizio \& Françoise Salager-Meyer (eds.) 2006. Advances in Medical Discourse Analysis: Oral and Written Contexts. Berna: Peter Lang, pp. 271-288.

HARWOOD, Amy E. \& Jayne E. Harrison. (2004) "How readable are orthodontic patient information leaflets?." Journal of Orthodontics 31, pp. 210-219.

HeDMAn, Amy S. (2008) "Using the SMOG formula to revise a health-related document." American Journal of Health Education 39:1, pp. 61-64.

HIRSH, Di; Rosemary Clerehan; Margaret Staples; Richard H. Osborne \& Rachelle Buchbinder. (2009) "Patient assessment of medication information leaflets: A reader-focused strategy to validate an analytic linguistic framework." Patient Education and Counselling 77, pp. 248-254.

Hoste, Véronique; Klaar Vanopstal; Els Lefever \& Isabelle Delaere. (2010) "Classification-Based Scientific Term Detection in Patient Information." Terminology 16:1, pp. 1-29.

Jensen, Matilde Nisbeth. (2012) "Patient Information Leaflet translators in the EU: Mapping the hypothetical competences of professional translator and pharmacists-cum-translators." En: Fischer, Beatrice \& Matilde Nisbeth Jensen 
(eds.) 2012. Translation and the reconfiguration of power relations. Revisiting role and context of translation and interpreting. Munich: Lit Verlag.

JENSEN, Matilde Nisbeth. (2013) Translators of Patient Information Leaflets: Translation experts or expert translators?: A mixed methods study of lay-friendliness. Aarhus: Aarhus University, Aarhus School of Business and Social Sciences. Tesis Doctoral. Versión electrónica: <http://pure.au.dk/portal/files/55635800/ Matilde_Nisbeth_Jensen_PhD_AU_final.pdf>

Koo, Michelle; Ines Krass \& Parisa Aslani. (2002) "Consumer opinions on medicines information and factors affecting its use - an Australian experience." The International Journal of Pharmacy Practice 10, pp. 112-114.

LEY, Philip \& Tony Florio. (1996) "The use of readability formulas in health care." Psychology, Health \& Medicine 1:1, pp. 7-28.

March Cerdá, Joan Carles; M. Ángeles Prieto Rodríguez; Ainoa Ruiz Azarosa; Pablo Simón Lorda; Inés Barrio Cantalejo \& Alina Danet. (2010) "Mejora de la información sanitaria contenida en los prospectos de los medicamentos: expectativas de pacientes y de profesionales sanitarios." Atención Primaria 42 , pp. 22-27.

MARTí FERRIOL, José Luís. (2016) "Selection and validation of a measurement instrument for readability calculations in patient information leaflets for oncological patients in Spain." Journal of Design and Statistics in Linguistics and Communication Science 3:1, pp. 1-16.

MARTínez Motos, Raquel. (2012) "Models of Quality Assessment for Patient Package Inserts in English and Spanish." En: Fischer, Beatrice \& Matilde Nisbeth Jensen (eds.) 2012. Translation and the reconfiguration of power relations. Revisiting role and context of translation and interpreting. Munich: Lit Verlag, pp. 259-277.

MARTÍNez Motos, Raquel. (2016) El género prospecto y el efecto de la traducción inglés-español en su legibilidad y facilidad de uso para el lector lego. Alicante: Universidad de Alicante. Tesis doctoral.

MerCado López, Sebastián. (2003a) “¿Constituyen un género los prospectos de medicamentos?” En: Luque et al. (eds.) 2003. Las lenguas en un mundo global. Jaén: Oficina de Publicaciones de la Universidad de Jaén.

Mercado López, Sebastián. (2003b) "Estructura y relación de poder en los prospectos de medicamentos vendidos en España." Estudios filológicos 38, pp. 93-110. Versión electrónica: <http://www.scielo.cl/scielo. php?script=sci_arttext\&pid=S0071-17132003003800006>

MERCADo LÓPEZ, Sebastián. (2004) "El análisis de géneros aplicado a la traducción: Los prospectos de medicamentos de Estados Unidos y España." Linguax: Revista de lenguas aplicadas 2:2, pp. 3-21. Versión electrónica: <https://revistas. uax.es/index.php/linguax/article/view/488/444> 
MontAlt i ResurReCció, Vicent \& Isabel García Izquierdo. (2002) "Translating into Textual Genres." Linguistica Antverpiensial, Linguistics and Translation Studies -Translation Studies and Linguistics 1, pp. 135-145.

Montalt i Resurrecció, Vicent. \& María González Davies. (2007) Medical Translation Step by Step. Vic: Eumo Editorial.

PANDER MAAT, Henk \& Lentz, Leo. (2010) "Improving the usability of patient information leaflets." Patient Education and Counseling 80, pp. 113-119.

PAnder MaAT, Henk \& Leo Lentz. (2011) "Using Sorting Data to Evaluate Text Structure: An Evidence-based Proposal for Restructuring Patient Information Leaflets." Technical Communication 58:3, pp. 197-216.

RAYNOR, D. K. Theo; Peter Knaap; Alexandra Moody \& Richard Young. (2005) "Patient information leaflets - Impact of European regulations on safe and effective use of medicines." Pharmaceutical Journal 275 (7375), pp. 609-611.

RUIZ GARRIDO, Manuel Francisco; Inmaculada Fortanet Gómez; Juan Carlos Palmer Silveira \& Ulla Connor. (2006) "Análisis contrastivo de la comunicabilidad del prospecto de los medicamentos en España y en Estados Unidos.” En: Gallardo, Beatriz; Carlos Hernández \& Verónica Moreno (eds.) 2006. Lingüística clínica y neuropsicología cognitiva. Actas del Primer Congreso Nacional de Lingüística Clínica. Vol 3. Lingüística interaccional en ámbitos de salud. Valencia: Universitat, pp. 140-152.

Ruiz Garrido, Miguel Francisco; Juan Carlos Palmer Silveira \& Inmaculada Fortanet Gómez. (2008) "El prospecto de medicamentos en España y EEUU: utilización de viñetas y abreviaturas." En: Campos Pardillos, Miguel Ángel \& Adelina Gómez-González Jover. (eds.) 2008. The Language of Health Care: Proceedings of the first International Conference on Language and Health Care, Alicante, 24-26 Octubre 2007. Alicante: IULMA. CD-ROM.

SuÁrEz Muñoz, Ángel \& Suárez Ramírez, Sergio. (2013) Legibilidad, lecturabilidad en Diccionario de nuevas formas de lectura y escritura. Madrid: Santillana.

SzIGRISZT Pazos, Francisco. (1993) Sistemas predictivos de legibilidad del mensaje escrito: Fórmula de Perspicuidad. Madrid: Universidad Complutense. Tesis doctoral. Versión electrónica: <http://biblioteca.ucm.es/tesis/19911996/S/3/ S3019601.pdf>

VARIOS autores (Agencia Española del Medicamento y Productos Sanitarios). (2010) Cómo se regulan los medicamentos y productos sanitarios en España. Versión electrónica: <http://www.aemps.gob.es/publicaciones/publica/regulacion_med-PS/docs/folleto-regulacion_Med-PS.pdf>

VARIOS autores (Agencia Europea del Medicamento). (2014) Compilation of QRD decisions on stylistic matters in product information. Versión electrónica: <http:// www.ema.europa.eu/docs/en_GB/document_library/Regulatory_and_procedural_guideline/2009/10/WC500004442.pdf> 
VARIOS autores (Asociación Española de Derecho Farmacéutico). (2007) La redacción del prospecto: recomendaciones para mejorar su comprensión. Madrid: ASEDEF.

VARIOS autores (Comisión Europea). (2009) Guideline on the readability of the labelling and package leaflet of medicinal products for human use. Versión electrónica: <http://ec.europa.eu/health/files/eudralex/ vol-2/c/2009_01_12_readability_guideline_final_en.pdf

VARIOS autores (Ministerio de Sanidad y Consumo). (2004) Por un uso racional del medicamento: Plan Estratégico de Política Farmacéutica para el Sistema Nacional de Salud Español. Versión electrónica: <http://www.aeseg.es/restringido2/ nuevo/notas/Plan_Estrategico_de_Sanidad_231104.pdf>

VARIOS autores (Unión Europea). (2001) Directiva 2001/83/CE del Parlamento Europeo y del Consejo de 6 de noviembre de 2001 por la que se establece un código comunitario sobre medicamentos para uso humano. Versión electrónica: <http://ec.europa.eu/health/files/eudralex/vol-1/dir_2001_83_cons/ dir2001_83_cons_20081230_es.pdf>

VARIOS autores (Unión Europea). (2004) Directiva 2004/27/CE del Parlamento Europeo y del Consejo de 31 de marzo de 2004 que modifica la Directiva 2001/83/CE por la que se establece un código comunitario sobre medicamentos para uso humano. Versión electrónica: <http://www.boe.es/doue/2004/136/ L00034-00057.pdf>

VÁZQUEZ Y DEL ÁRBOL, Esther. (2013) "Traditional patient information leaflet frente al prospecto medicamentoso tradicional: el orden de los factores ¿no altera? el valor del producto." Panace@ 14:37, pp. 89-97. Versión electrónica: <http:// www.medtrad.org/panacea/IndiceGeneral/n37-tribuna-EVazquezydelArbol. pdf>

VÁZQUEZ Y DEL ÁRBOL, Esther. (2014) "Modern user information leaflet frente al prospecto medicamentoso: el orden de los factores ¿no altera? el valor del producto (segunda parte).”Panace@ 15:39, pp. 118-127. Versión electrónica: <http://www.medtrad.org/panacea/IndiceGeneral/n39-tribuna_VazquezydAE. pdf> 


\section{NOTA BIOGRÁFICA / BIONOTE}

RAQUEl MARTínez Motos es licenciada en Traducción e Interpretación por la Universidad de Granada y doctora en Traducción e Interpretación por la Universidad de Alicante. Asimismo, es traductora-intérprete jurada de lengua inglesa. Desde 2004 desarrolla su labor docente como Profesora Contratada Doctora en el Departamento de Filología Inglesa de la Universidad de Alicante, donde actualmente imparte clases de traducción general, traducción jurídica e inglés para fines específicos. En 2007 publicó el Diccionario Terminológico de las Ciencias Farmacéuticas (inglés/español) junto con el doctor Enrique Alcaraz Varó y el doctor Alfonso Domínguez-Gil Hurlé, patrocinado por la Real Academia Nacional de Farmacia. Sus principales líneas de investigación se centran en terminología, traducción jurídica y científica e inglés para fines específicos.

RaQuel Martínez Motos holds a BA in Translation and Interpreting from the University of Granada and a PhD in Translation and Interpreting from the University of Alicante. She is also accredited as a Sworn Translator and Interpreter of English. She has been working as a lecturer at the English Department of the University of Alicante since 2004, where she currently teaches general translation, legal translation and English for Specific Purposes. In 2007 she published A Terminological Dictionary of the Pharmaceutical Sciences (English-Spanish), co-authored with Dr. Enrique Alcaraz Varó and Dr. Alfonso Domínguez-Gil Hurlé and sponsored by the Spanish Royal Academy of Pharmacy. Her main lines of research are focused on terminology, legal and scientific translation and language for specific purposes. 
